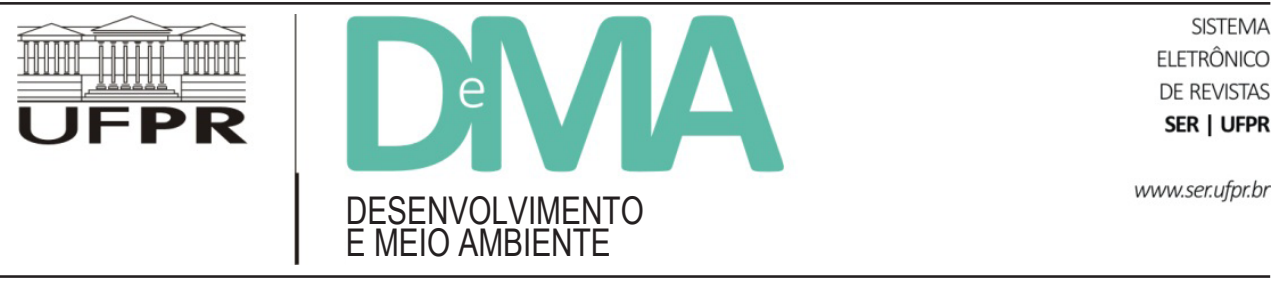

\title{
Sistemas tradicionais de manejo de sementes crioulas e o cenário brasileiro de proteção de variedades e certificação de orgânicos: estudo de caso da Rede Agroecológica Metropolitana de Porto Alegre, Rio Grande do Sul
}

\section{Traditional Management Systems of Landrace Seeds and Brazilian Scenario of Protection of Varieties and Organic Certifications: case study of Rede Agroecológica Metropolitana of Porto Alegre, Rio Grande do Sul}

\author{
Mariana Luiz PROENÇA ${ }^{1}$, Gabriela COELHO-DE-SOUZA ${ }^{1 *}$ \\ ${ }^{1}$ Núcleo de Estudos em Desenvolvimento Rural Sustentável e Mata Atlântica (DESMA), Universidade Federal do Rio Grande do Sul (UFRGS), \\ Porto Alegre, RS, Brasil. \\ *E-mail de contato: gabriela.coelho@pq.cnpq.br
}

Artigo recebido em 19 de janeiro de 2016, versão final aceita em 18 de novembro de 2016.

RESUMO: Os sistemas tradicionais de manejo das sementes crioulas vêm sofrendo transformações em face do atual cenário brasileiro de proteção de cultivares e certificações de orgânicos. Nesse contexto, objetivou-se discutir a vulnerabilidade desses sistemas diante dos marcos legais que legitimam e empoderam o sistema formal de sementes e que impõem exigências para os processos de certificação de produtos orgânicos, a partir do estudo de caso do Organismo Participativo de Avaliação da Conformidade Orgânica, vinculado à Associação dos Produtores da Rede Agroecológica Metropolitana (Opac-Rama) de Porto Alegre, no Rio Grande do Sul. Percebe-se que, apesar da forte pressão que a legislação de proteção de cultivares exerce sobre os processos de autonomia dos agricultores, buscando mantê-los dentro de um sistema hegemônico de produção convencional, a atual legislação de orgânicos está incentivando a retomada do manejo de sementes crioulas. Portanto, os direitos dos agricultores aos seus conhecimentos e práticas de manejo de suas sementes crioulas estão resistindo e buscando se viabilizar, fortalecendo, assim, os processos agroecológicos.

Palavras-chave: conhecimento tradicional; agrobiodiversidade; sistemas de sementes crioulas; proteção de variedades.

ABSTRACT: The traditional management systems of landrace seeds have undergone transformations in the current Brazilian scenario of protection of varieties and organic certifications. In this context, the objective of this work is to discuss the vulnerability of these systems when facing the legal frameworks that legitimize and empower the formal seeds system and imposes requirements for the certification process of organic products, from the case study of Organismo Participativo de Avaliação da Conformidade Orgânica, linked to the Associação dos 
Produtores da Rede Agroecológica Metropolitana (OPAC-RAMA) of Porto Alegre, Rio Grande do Sul. It is noticed that, despite the strong pressure from the legislation of varieties protection on the processes of autonomy of the farmers trying to keep them within a hegemonic system of conventional production, the current legislation of organics is encouraging the resumption of handling landrace seeds. Therefore, farmers' rights to their knowledge and management practices of their landrace seeds are resisting and seeking to become viable, strengthening the agro-ecological processes.

Keywords: traditional knowledge; agrobiodiversity; systems of landrace seeds; variety protection.

\section{Introdução}

Este artigo tem por finalidade discutir a vulnerabilidade dos sistemas tradicionais de manejo de sementes crioulas em face do atual cenário brasileiro de proteção de cultivares e certificação orgânica. Para estudar esse contexto, parte-se do estudo de caso do manejo das sementes crioulas ${ }^{1}$ pelo Organismo Participativo de Avaliação da Conformidade Orgânica, vinculado à Associação dos Produtores da Rede Agroecológica Metropolitana (Opac-Rama) de Porto Alegre, no Rio Grande do Sul. O artigo está organizado em cinco seções. Na primeira, é apresentado o contexto dos conhecimentos e práticas tradicionais na condução dos processos de domesticação de variedades crioulas. A segunda apresenta os marcos legais que instituem o confronto entre os direitos dos agricultores ao manejo de suas variedades crioulas e a proteção das variedades tecnificadas. A terceira seção discute as exigências para os processos de certificação de produtos orgânicos e a organização dos produtores agroecológicos da região metropolitana de Porto
Alegre. A quarta seção apresenta a experiência do manejo e circulação das sementes crioulas pelo Opac-Rama. Por fim, apresentam-se as considerações finais retomando a questão da vulnerabilidade dos sistemas tradicionais de manejo de sementes crioulas, a partir do caso do Opac-Rama.

\section{Conhecimentos e práticas tradicionais e a domesticação de variedades crioulas}

A agricultura surgiu em diferentes regiões ao redor do mundo ao longo do período neolítico, há cerca de 12 mil anos, por meio de um conjunto complexo de condições ecológicas, sociais e culturais. Os grandes centros de origem da Revolução Neolítica coincidem com áreas de maiores adensamentos populacionais e as áreas de domesticação. Entre 12 mil e 7 mil anos atrás, algumas sociedades neolíticas haviam começado a semear plantas e a manter animais em cativeiros com a intenção de produção. É provável que as primeiras semeaduras tenham sido feitas ao redor das casas de forma acidental, e, ainda que

\footnotetext{
De acordo com Machado et al. (2008), as sementes crioulas caracterizam-se por uma constante adaptação ao meio e às técnicas de manejo adotadas pelos agricultores. No Brasil, oficialmente, é considerado "cultivar local, tradicional ou crioula: toda aquela variedade desenvolvida, adaptada ou produzida por agricultores familiares, assentados da reforma agrária ou indígenas, com características fenotípicas bem determinadas e reconhecidas pelas respectivas comunidades e que, a critério do Mapa, considerados também os descritores socioculturais e ambientais, não se caracterizem como substancialmente semelhantes às cultivares comerciais” (Brasil, 2003a). Sendo assim, os critérios para a identificação das sementes locais, crioulas ou tradicionais devem ser também definidos pelas próprias comunidades de agricultores, em consonância com suas práticas de manejo, seleção e melhoramento genético e levando-se em consideração a natureza intrínseca e a heterogeneidade genética de tais sementes (Machado et al., 2008).
} 
os primeiros agricultores soubessem reconhecer e preservar certas linhagens de plantas, a domesticação teria surgido, então, como um resultado não premeditado, inconcebível a priori (Mazoyer \& Roudart, 2010).

A domesticação, por ser um processo coevolucionário, ocorre de forma lenta e gradual, sendo a ação de plantar a principal chave do processo, principalmente em se tratando de cultivares com sementes. O simples ato de plantar aciona uma pressão de seleção interconectada, que atua sobre os caracteres de interesse, constituindose em um processo extremamente eficiente, artificial e por vezes "caprichoso" (Harlan, 1992). Clement (1999) apresenta cinco categorias para os graus de alteração de uma população manejada: a) selvagem; b) coevoluída acidental; c) domesticada incipiente; d) semidomesticada; e e) domesticada. Nessas categorias, a seleção aparece nas três últimas formas, sendo que a maior pressão de seleção e a perda de adaptação ecológica tornam a população domesticada hábil a sobreviver apenas em ambientes alterados, especialmente em cultivos. $\mathrm{O}$ autor alerta para o fato de que tais categorias representam grupos ideais, que por vezes ilustram imperfeitamente o mundo real, já que a domesticação é um contínuo de investimentos humanos em seleção e em manipulação do ambiente.

Para haver domesticação são necessários manejo e seleção, capazes de promover reprodução diferencial e sobrevivência, práticas possíveis por meio dos conhecimentos tradicionais, que fazem do processo de domesticação também um processo cultural (Clement, 1999). Como destaca Shiva (1993), a diversidade cultural e a diversidade biológica andam de mãos dadas. É nessa mesma lógica que Peroni \& Hanazaki (2002) argumentam que a complexidade de um sistema agrícola reflete a com- plexidade do sistema de conhecimentos necessários para manejá-lo, considerando que uma alta taxa de diversidade biológica manejada requer um conjunto mais diverso de conhecimentos com relação, por exemplo, à seleção diferenciada, a diferentes usos, a diferentes épocas de plantio.

De acordo com Clement (1999), existe uma forte relação entre a paisagem e a domesticação de plantas nas Américas, evidente por meio de gradientes de alterações populacionais e ambientais correlacionados. Gradientes de alterações da paisagem são categorizados pelo autor em: paisagens prístinas, paisagens promovidas, paisagens manejadas e paisagens cultivadas. As paisagens cultivadas constituem uma categoria que envolve alterações na biota com fins de favorecer o desenvolvimento de uma ou poucas espécies de interesse, que, por sua vez, têm sua condição de sobrevivência totalmente dependente da intervenção humana.

De acordo com Amorozo (2013), agricultores tradicionais, que têm a agricultura como subsistência, são pesquisadores locais que possuem conhecimentos e práticas de grande profundidade sobre o manejo e a condução de processo de domesticação de variedades. Segundo Begossi (1998, apud Peroni \& Hanazaki, 2002), o manejo tradicional das roças pelos caiçaras é um exemplo de prática que aumenta a resiliência das comunidades e dos ecossistemas. Cunha (2009), ao abordar a produção de diversidade biológica por povos indígenas, evidencia a coevolução da diversidade biológica e da diversidade sociocultural.

A agrobiodiversidade é o resultado da coevolução das dinâmicas e das relações entre plantas cultivadas, o ambiente e os atores sociais envolvidos e possui componentes-chave como processos culturais, conhecimentos, práticas e inovações agrícolas desenvolvidos e compartilhados pelos agricultores (Santilli, 2009). Pelo caráter diver- 
so e adaptativo biológica e socioculturalmente, a agrobiodiversidade é importante para todas as formas de produção agrícola, sendo possível explorar diferentes ambientes e manter relativa estabilidade de produção em face de ataques de pragas e instabilidades climáticas (Amorozo, 2013). O conceito repercute sobre as políticas de conservação, inclusão social e desenvolvimento local sustentável, além de ser essencial à promoção da segurança e da soberania alimentar (Santilli, 2009).

\section{Sementes crioulas $x$ sementes tecnificadas: marcos legais que instituem o confronto}

Comunidades por todo o mundo desenvolveram conhecimentos e modos de vida associados à diversidade biológica, selvagem e domesticada. Hoje, no entanto, a diversidade dos ecossistemas e dos conhecimentos tradicionais está sob ameaça de extinção. Habitats têm sido destruídos, a diversidade tem sido erodida e formas de vida derivadas da biodiversidade estão condenadas (Shiva, 1993). A perda dos conhecimentos dos grupos locais sobre as variedades e o manejo de sua propagação impossibilita a manutenção da agrobiodiversidade. De acordo com Clement (1999), as populações domesticadas desaparecem, sem o manejo dos grupos que tradicionalmente o praticam, sofrendo contração populacional e genética, ou regressando ao seu genótipo selvagem. Segundo o Relatório sobre o estado dos recursos genéticos de plantas do mundo, apresentado durante a $4^{\text {a }}$ Conferência Técnica Internacional sobre os Recursos Fitogenéticos, realizada em 1996, na Alemanha, os agricultores perderam, nos últimos cem anos, entre $90 \%$ e $95 \%$ de suas variedades agrícolas, devido, em grande parte, à substituição das variedades locais e tradicionais por variedades "modernas", de alto rendimento e estreita base genética (Santilli, 2009).

Segundo Goodman et al. (1990), com a descoberta da hibridização, no início do século XX, os setores agroindustriais passaram a adaptar suas estratégias de crescimento, incorporando a pesquisa e o desenvolvimento tecnológico sobre as sementes híbridas e a biotecnologia. A tendência do sistema agrícola convencional, atualmente presente em todas as terras agricultáveis do mundo, é a integração dos agricultores ao mercado como consumidores dos "pacotes" tecnológicos, que disponibilizam maquinários, insumos químicos, sementes híbridas e/ou transgênicas. Nesse modelo, as sementes representam um insumo estratégico de incorporação e dependência dos agricultores a esse sistema, já que a segunda geração das sementes híbridas tende a perder o vigor híbrido.

As variedades tecnificadas promovidas pela Revolução Verde pertencem a um paradigma reducionista que externaliza os custos e os impactos do sistema e desconsidera a diversidade de usos que os sistemas tradicionais de cultivo dão a sua produção total, considerando no cálculo do rendimento apenas a produção voltada aos interesses comerciais (Shiva, 1993). Tais variedades são produzidas para obter maior rendimento em sistemas agrícolas modernos por meio de uma maior sensibilidade à aplicação de fertilizantes, em contraposição às variedades locais que possuem baixa sensibilidade ao uso de fertilizantes. O processo rural de trabalho já não é mais tão determinado pelo ritmo da máquina quanto é governado pela capacidade que os capitais industriais possuem de modificar os ritmos do tempo biológico, intervindo na base genética estabelecida por processos antiquíssimos (Goodman et al., 1990).

Shiva (1993) alerta que a diversidade contida nos sistemas de cultivos autóctones é insubstituível. 
O pacote da Revolução Verde substitui a diversidade genética, primeiro, por substituir policulturas por monoculturas e, segundo, por utilizar variedades de estreitíssima base genética em comparação com as variedades tradicionais. A destruição da diversidade e a criação da uniformidade envolvem simultaneamente a destruição da estabilidade e a criação da vulnerabilidade, resultando em sistemas simplificados e frágeis. Além disso, a inovação representada pelas sementes tecnificadas, apesar de ter incentivos públicos em muitos países, deixou de fora do processo de industrialização agrícola muitos agricultores tradicionais que não puderam adquirir os novos meios de produção e, em consequência, favoreceu o empobrecimento e o êxodo rural (Mazoyer \& Roudart, 2010).

Para Shiva (1993), o problema vai além da tecnologia e dos programas que mantêm esse modelo e está enraizado na ideologia dominante, que traz a convicção absoluta de que esse paradigma é a solução para os problemas de todos os lugares do planeta, desconsiderando especificidades locais no que diz respeito à geografia, aos ecossistemas, ao clima e às populações. A monocultura da mente, ou seja, o sistema de conhecimento moderno, tido como o único científico, universal e, portanto, legítimo, é responsável pelo desaparecimento do conhecimento local. Primeiro, pelo simples fato de não o tornar visível, negando sua existência,e, segundo, porque, quando o conhecimento tradicional ou local é visível, é considerado, então, primitivo, não científico, ilegítimo. Ainda segundo a autora, apenas uma agronomia tendenciosa e enraizada no patriarcado capitalista poderia considerar como "marginais", "inferiores" e "de má qualidade" cultivares nutritivos que há muito tempo constituem a base alimentar de diversas comunidades locais, tendo evoluído junto destas.
Em contraposição a esse reconhecimento dos direitos dos agricultores está a Convenção da União Internacional para a Proteção das Obtenções Vegetais (Upov), aprovada em 1961 (revista em 1972, 1978 e 1991), com o objetivo de assegurar, cada vez mais, a proteção efetiva aos direitos dos obtentores vegetais. Em consequência, os espaços legais para práticas agrícolas tradicionais, como guarda de sementes para replantio e intercâmbio delas, estão sendo cada vez mais reduzidos (Santilli, 2009). Em nível nacional, a Lei $n^{\circ} 9.456$, de 25 de abril de 1997, que institui a Lei de Proteção de Cultivares e dá outras providências (Brasil, 1997), e a Lei ${ }^{\circ} 10.711$, de 5 de agosto de 2003, que dispõe sobre o Sistema Nacional de Sementes e Mudas e dá outras providências (Brasil, 2003a), ambas com princípios baseados na Convenção da Upov, regulamentam o sistema formal de sementes, negando o papel dos agricultores como inovadores e detentores de saberes e práticas fundamentais para a agricultura e excluindo as variedades locais da proteção e também da produção e comercialização por não preencherem os requisitos legais de homogeneidade e estabilidade. Ainda que contenham brechas quanto à utilização das sementes tradicionais e crioulas, as leis não traçam meios de incentivos e impõem dificuldades à distribuição e ao acesso, assim como ao uso de sementes que não preenchem os critérios necessários, como a ausência da garantia de seguro agrícola para cultivos que utilizam sementes tradicionais e/ou crioulas (Santilli, 2009).

Contrapondo o sistema agrícola hegemônico moderno, surgem nos anos 1980, no Brasil e na América Latina, projetos promovidos por ONGs que incorporam elementos dos conhecimentos tradicionais e da ciência agrícola moderna, voltados para a conservação dos recursos e para a elaboração de sistemas altamente produtivos de policulturas, de agroflorestas e de integração lavoura-pecuária. 
A partir do final da década de 1990, movimentos camponeses e rurais têm adotado a agroecologia como bandeira de sua estratégia de desenvolvimento e soberania alimentar (Altieri, 2012).

O crescente reconhecimento do papel dos agricultores e das comunidades locais na conservação da agrobiodiversidade, ao longo da década de 1990, consolidou o pensamento sobre o papel vital das "tradições" em uma "abordagem ecossistêmica" para a agricultura, enfatizando a sustentabilidade e os serviços ecológicos fornecidos pela agricultura em pequena escala. Assim, surgiu a necessidade de um regime jurídico diferenciado, capaz de solucionar os problemas específicos relacionados aos recursos fitogenéticos para alimentação e agricultura. É então, durante a $31^{\mathrm{a}}$ Reunião da Conferência da Organização das Nações Unidas para a Alimentação e a Agricultura (FAO), realizada em 2001, em Roma, que se acorda o Tratado Internacional sobre os Recursos Fitogenéticos para a Alimentação e para a Agricultura (Tirfaa). $\mathrm{O}$ tratado visa à conservação e ao uso sustentável da agrobiodiversidade, preocupando-se com a repartição justa e equitativa dos benefícios derivados de sua utilização para uma agricultura sustentável e a segurança alimentar (Coupe \& Lewins, 2007).

O Tirfaa faz referência à Declaração de Roma sobre Segurança Alimentar Mundial e ao Plano de Ação da Cúpula Mundial sobre a Alimentação assinado por chefes de Estado durante a Cúpula Mundial sobre a Alimentação da FAO, em 1996, em Roma. Os países comprometeram-se a realizar esforços permanentes para erradicar a fome, assumindo que o principal problema está na dificuldade de acesso aos alimentos, apesar da crescente produção alimentar. Dentre os compromissos assumidos pelos governos está a promoção ao acesso dos agricultores aos recursos genéticos. Declaração e plano destacam a importância de assegurar que o fornecimento de alimentos seja seguro, acessível, apropriado e adequado às necessidades energéticas e nutricionais da população (Declaração de Roma sobre a Segurança Alimentar Mundial e Plano de Acção da Cimeira Mundial da Alimentação, 1996), o que contribui para a conscientização de que a fome e a subalimentação só serão erradicadas quando o acesso aos recursos fitogenéticos for devidamente assegurado às comunidades agrícolas, livre de restrições, e a diversidade genética for conservada não só ex situ, como também in situ e on farm ${ }^{2}$ com a participação dos agricultores (Santilli, 2009).

\section{Certificação de produtos da agricultura orgânica e a organização dos produtores agroecológicos da região metropolitana de Porto Alegre}

No Brasil, a discussão entre a sociedade civil organizada e o poder executivo para a regulamentação da agricultura orgânica tem início em 1994 e, como resultado, é oficialmente reconhecida em maio de 1999, por meio da publicação da Instrução

\footnotetext{
2 Para Brush (2008), a conservação genética de culturas ex situ considera a manutenção de recursos genéticos em bancos de genes, jardins botânicos e estações de pesquisa agrícola. Por outro lado, a conservação in situ refere-se à manutenção dos recursos genéticos nas propriedades ou em habitats naturais. Segundo o autor, a conservação in situ tanto pode ser considerada um fenômeno histórico quanto referir-se a projetos e programas específicos (patrocinados por governos nacionais e internacionais e organizações privadas para apoiar e promover a manutenção da diversidade de culturas) concebidos para influenciar os agricultores na direção da manutenção das culturas locais, utilizando técnicas que podem não ser locais. Para esse autor, conservação in situ é sinônimo de conservação on farm. Já para a Convenção da Diversidade Biológica (1992), a conservação in situ, no caso de espécies domesticadas ou cultivadas, ocorre apenas nos meios onde as variedades tenham desenvolvido suas propriedades características, não considerando o termo on farm.
} 
Normativa (IN) no 007/99 do Ministério da Agricultura, Pecuária e Abastecimento (Mapa), que dispõe sobre normas para a produção de produtos orgânicos vegetais e animais. Em dezembro de 2003, após tramitação no Congresso Nacional, com a participação democrática de representantes do setor, organizações públicas e privadas e da sociedade civil, foi publicada a Lei ${ }^{\circ} 10.831$ (Brasil, 2003b), que dispõe sobre a agricultura orgânica e dá outras providências, definindo e estabelecendo condições obrigatórias para a produção e a comercialização de produtos da agricultura orgânica (Fonseca, 2009).

O Decreto Federal n ${ }^{\circ}$ 6.323/07 (Brasil, 2007a) institui o Sistema Brasileiro de Avaliação da Conformidade Orgânica (SisOrg), que tem como integrantes órgãos e entidades da administração pública federal (também os estaduais e o distrital, se conveniados), e os OACs (Organismos de Avaliação da Conformidade Orgânica) credenciados pelo Mapa. O Opac (Organismo Participativo de Avaliação da Conformidade Orgânica) é uma forma de certificação por Sistema Participativo de Garantia (SPG), em que o próprio grupo garante a qualidade de seus produtos e compartilha as responsabilidades entre produtores, técnicos, consumidores e fornecedores.

No Rio Grande do Sul, o Opac-Rama teve início com a organização da Associação de Produtores Ecologistas do Lami (Apel), inicialmente com a participação de nove famílias, em 1999. Mediante trabalho de extensão desenvolvido pela Empresa de Assistência Técnica e Extensão Rural do Rio Grande do Sul (Emater/RS-Ascar) no local, na época com apoio do Centro Agrícola Demonstrativo de Porto Alegre, da Secretaria Municipal da Indústria e Comércio (CAD/SMIC), em parceria com o Centro Ecológico de Ipê, agregaram-se outros sete grupos da região Sul da cidade, totalizando 40 famílias. As exigências da legislação de orgânicos, na época regulamentados pela IN $n^{\circ}$ 64/08 (Mapa, 2008), posteriormente substituída pela IN no 46/11 (MAPA, 2011) e pela IN n ${ }^{\circ} 17 / 14$ (MAPA, 2014), estimularam a unificação desses grupos, agregando novos produtores a partir da necessidade de organizarem-se dessa forma para o cadastramento de produtores orgânicos como Organismos de Controle Social (OCSs) (Uriartt et al., 2011). Sendo assim, em 2010, agricultores, consumidores e técnicos de Porto Alegre e Viamão se uniram no processo de construção do OCS Porto Alegre/Viamão. No entanto, como não eram todas as famílias que se enquadravam como agricultores familiares segundo o Programa Nacional da Agricultura Familiar (Pronaf) - condição para se cadastrarem como produtores orgânicos por meio de um OCS -, o grupo iniciou a formação do Opac-Rama, que congrega também os demais agricultores (Rama, 2012).

Os integrantes estão divididos em fornecedores (produtores e processadores) e colaboradores (técnicos e consumidores $)^{3}$ que participam do processo de certificação. Atualmente, o Opac-Rama conta com aproximadamente 40 famílias de fornecedores, pertencentes aos municípios de Guaíba, Eldorado do Sul, Porto Alegre, Viamão, Cachoeirinha, Alvorada, Gravataí e Glorinha. O grupo possui

\footnotetext{
3 Os fornecedores são responsáveis por: solicitar a avaliação da conformidade de seus produtos; fornecer as informações necessárias com os detalhes e a frequência pedidos pelo SPG e exigidos pelo Opac; atender a todas as orientações de prevenção e providenciar a correção das não conformidades; e garantir que tanto os seus produtos quanto os do grupo estarão de acordo com os regulamentos da produção orgânica. Aos colaboradores corresponde a função de assumir a responsabilidade solidária pelos produtos avaliados, sendo que todos os participantes devem contribuir para a geração de credibilidade, por meio da participação ativa no SPG (MAPA, 2016).
} 
grande rotatividade entre seus participantes e se distingue pela proximidade com a cidade, com um forte caráter rural-urbano, sendo formado por pessoas com históricos distintos entre si. O processo de certificação participativa é acompanhado por extensionistas da Emater/RS-Ascar, do CAD/ SMIC, do Mapa, da Universidade Federal do Rio Grande do Sul (UFRGS) e da Secretaria Estadual de Desenvolvimento Rural, Pesca e Cooperativismo (SDR-RS), que colaboram para definir as linhas de atuação, além dos objetivos e parâmetros do mecanismo de avaliação e controle social.

Uma das questões que têm preocupado os agricultores orgânicos e técnicos que participam do credenciamento de produtores orgânicos junto ao Mapa é a IN no 46, de 6 de outubro de 2011, regulamentada pela IN n ${ }^{\circ}$ 17/14 (MAPA, 2014), que estabelece o regulamento técnico, bem como as listas de substâncias permitidas para uso nos sistemas orgânicos de produção animal e vegetal. A partir de dezembro de 2013, essa IN passaria a proibir o uso, em sistemas orgânicos, de sementes e mudas que recebessem, da produção à armazenagem, tratamento com agrotóxicos ou com outros insumos não permitidos pela IN, porém houve prorrogação do prazo, sem uma definição até o momento presente. Entre os motivos para a prorrogação está a indisponibilidade de acesso a sementes orgânicas para atender à demanda dos agricultores certificados ou em processo de certificação (MAPA, 2014).

Uma das estratégias que o Opac-Rama está adotando para manter suas sementes refere-se à Arca de Sementes Berenice Antonini. A arca está prevista no regimento interno do Opac-Rama, no entanto é anterior à própria existência da Rama, tendo sido oficialmente lançada em 2009, sob o nome de Berenice Antonini, em uma homenagem póstuma. Berenice, antiga integrante do grupo e grande entusiasta das sementes, desenvolveu um trabalho de catalogação de sementes, iniciativa que fez com que fosse presenteada com sementes de diferentes regiões ao redor do mundo. Ela organizou sua coleção e um mostruário com os exemplares para expor em encontros e eventos. Berenice foi quem primeiro propôs as trocas de sementes dentro do grupo e pretendia montar um banco de sementes para fornecimento e troca com outros interessados em resgatar o cultivo delas. Atualmente, o trabalho da arca se mantém por meio da conservação feita pelos sementeiros do grupo - cujo número chegou a 30 responsáveis por 40 variedades - e por meio do evento Troca Anual de Sementes, que ocorre anualmente durante a Semana dos Alimentos Orgânicos, realizada na última semana de maio.

\section{A experiência do Opac-Rama no manejo e na circulação das sementes crioulas}

Para compreender o papel da Rama sobre a autonomia e a manutenção dos conhecimentos e práticas sobre o manejo das sementes crioulas, foi realizado um estudo etnobotânico e analisada a percepção dos agricultores sobre a autonomia da produção de sementes pelo Opac-Rama.

A metodologia dessa etapa da pesquisa consistiu, inicialmente, em participação nas plenárias mensais da Opac-Rama desde abril de 2014 e na IV Troca Anual de Sementes da Arca de Sementes Berenice Antonini, em maio de 2014, em que se deram os primeiros contatos com a questão. Em um segundo momento, houve participação nos módulos I e II do Curso sobre Produção Agroecológica de Sementes de Hortaliças para Autoabastecimento na Agricultura Familiar, direcionado à produção agroecológica de sementes de hortaliças, promovido pela SDR-RS, Emater e parceiros (UFRGS, CAPAErechim, Mapa/SFA-RS/CPOrg-RS) e realizado 
nos dias 29 e 30 de outubro de 2014 e 11 e 12 de dezembro de 2014, em Porto Alegre e Candiota, respectivamente. Para aprofundamento na questão, foram realizadas entrevistas semiestruturadas (A1buquerque \& Lucena, 2004) com nove integrantes do Opac-Rama: seis são fornecedores e três são colaboradores. Entre eles há um técnico da Emater e duas técnicas da SDR, mais um consumidor. Por fim, houve participação na V Troca Anual de Sementes, em maio de 2015.

Os dados obtidos a partir das entrevistas e do diário de campo redigido a partir da participação nos eventos junto ao grupo foram submetidos a análise de conteúdo (Bardin, 1977). O reconhecimento das sementes crioulas partiu da definição dos agricultores como aquelas determinadas e apropriadas pelo grupo, sendo consideradas as variedades antigas a partir de critérios distintos, como a heterogeneidade fenotípica da variedade, o tempo de manejo e os processos de seleção sobre as sementes. As variedades crioulas manejadas pelo grupo de agricultores foram reconhecidas ao nível de etnoespécie (Medeiros \& Albuquerque, 2012) e caracterizadas quanto ao tempo de manejo, tipo de propagação e procedência.

Os agricultores da associação da Rama são majoritariamente horticultores, produzindo hortaliças, geralmente de ciclo curto. Todos os produtores produzem pelo menos alguma variedade de sementes/mudas, sendo que as variedades mais recorrentes foram hibisco, morango, pimenta-doce e o tomate-perinha. Foram citadas ao todo 69 variedades produzidas e mantidas pelo grupo, sendo que dois dos seis produtores entrevistados terceirizam a produção de mudas de dez dessas variedades. Do total, 49,3\% (34 variedades) foram consideradas crioulas - incluindo oito plantas alimentícias não convencionais (Pancs) -, em sua maioria comercializadas em pequena escala, quando não servem apenas para consumo das próprias famílias, destacando-se aqueles agricultores com perfil sementeiro e de guardião de sementes, responsáveis pela manutenção de grande parte dessas variedades. Do total de 69 variedades, 13 são multiplicadas por meio de propágulos vegetativos (Figura 1), sendo que 11 delas são crioulas (Tabela 1). Destacam-se algumas variedades antigas adquiridas há mais de 30 anos (alho-nira, cebola-verde, ervilha-torta, espinafre, fava, melão, milho crioulo, mostarda, radite, salsa), que em sua maioria são aquisições feitas por meio de vizinhos ou familiares.

Duas produtoras entrevistadas citaram espécies de plantas que não são comuns no mercado, consideradas por Kinupp (2008) como Pancs. Esses produtos da agrobiodiversidade servem para o consumo da família e também são comercializados na feira ecológica, embora em menor quantidade. Algumas dessas variedades praticamente não dependem da ação direta do ser humano para propagarem-se, embora muitas sejam promovidas em áreas alteradas pela intervenção humana. As produtoras manejam variedades como radite [Hypochaeris chillensis (Kunth) Britton], capuchinha (Tropaeolum majus L.) e pepininho-do-mato (Melothria cucumis Vell.), das quais coletam sementes para cultivá-las em locais desejados, promovendo a propagação dessas variedades. $\mathrm{O}$ aproveitamento econômico dessas espécies, consideradas semidomesticadas ou de domesticação incipiente por Clement (1999), é defendido por Kinupp (2008) pelo potencial de contribuir para o enriquecimento da dieta alimentar humana e pelo incremento da matriz agrícola brasileira, contribuindo com a segurança alimentar e nutricional, em conciliação com o acordado pelos chefes de Estado e de governo na Declaração de Roma sobre a Segurança Alimentar Mundial (1996), principalmente com relação ao incentivo a utilizarem os recursos disponíveis de 
forma economicamente sólida e sustentável. Além disso, cultivar essas variedades pode representar menor dependência do mercado de sementes e de produção de mudas, por estas apresentarem características selvagens.
Todos os produtores entrevistados declararam fazer seleção, ainda que seja em casos específicos, a partir de critérios empíricos, normalmente relacionados à beleza dos frutos e à saúde das plantas. Apenas um agricultor declarou ter um cuidado na

TABELA 1 - Tempo de manejo, tipo de propagação e procedência de variedades crioulas manejadas pelos agricultores do Opac-Rama.

\begin{tabular}{|c|c|c|c|}
\hline Variedades & Tempo de manejo & Tipo de propagação & Procedência $* * *$ \\
\hline Abóbora-menina & 6-7 anos & semente & sem procedência \\
\hline Abóbora-rajada & 6-7 anos & semente & sem procedência \\
\hline Alho-nira & 30 anos & vegetativa & T - Panambi \\
\hline Amora-do-mato (groselha) & nativa* & vegetativa/espontânea & nativa* \\
\hline Batata-doce & 30 anos & vegetativa & $\mathrm{T}$ \\
\hline Batata-doce laranja & 10 anos & vegetativa & $\mathrm{C}-\mathrm{F}$ \\
\hline Batata-doce roxa & $8-9$ anos & vegetativa & $\mathrm{C}-\mathrm{F}$ \\
\hline Bucha vegetal & 10 anos & semente & $\mathrm{T}$ - Rama \\
\hline Capuchinha & $15+10$ anos & semente/espontânea** & $\mathrm{T}$ - França \\
\hline Cará-aéreo & 10 anos & vegetativa & D - UFRGS \\
\hline Ervilha-torta & aprox. 30 anos & semente & C-agrop \\
\hline Espinafre & 30 anos & vegetativa/espontânea & $\mathrm{T}$ \\
\hline Fava & aprox. 30 anos & semente & C-agrop \\
\hline Lágrima-de-nossa-senhora & aprox. 20 anos & semente/espontânea & $\mathrm{T}$ \\
\hline Mandioca-cascuda & 4 anos & vegetativa & $\mathrm{T}$ \\
\hline Melão & 35 anos & semente & $\mathrm{T}$ \\
\hline Menstruncio & nativa* & semente/espontânea & nativa* \\
\hline Milho-amarelo & 5 anos & semente & T - Piratini \\
\hline Milho-crioulo & 40 anos & semente & $\mathrm{T}$ - Ibiruba \\
\hline Mostarda & 40 anos & semente/espontânea** & $\mathrm{T}$ \\
\hline Radite & 30 anos & semente/espontânea** & $\mathrm{T}$ - Panambi \\
\hline Salsa & 40 anos & semente & $\mathrm{T}-\mathrm{POA}$ \\
\hline Serralha & nativa* & semente/espontânea & nativa* \\
\hline
\end{tabular}


seleção de praticamente todas as espécies de sua produção, tendo o costume de sempre deixar alguns indivíduos sementar na roça após a colheita, hábito que para os outros produtores costuma ser praticado com espécies mais pontuais. Não foram citadas muitas práticas relacionadas às sementes. Algumas que surgiram nas entrevistas disseram respeito a sementes de Curcubitaceae e Solanaceae, que, como os tomates, são fermentados e postos de molho para separar a mucilagem ou então simplesmente são secos à sombra, em local ventilado. Não existem regras. Alguns produtores observam a umidade do ar para decidir como vão secar suas sementes - se vão colocá-las ao sol ou à sombra - com base em métodos empíricos e em sua experiência acumulada em anos de prática.

As sementes/mudas manejadas pelos agricultores são adquiridas por meio de trocas e/ou presentes de amigos (49\%) ou doações de instituições (20\%) e compras em eventos/feiras de agrobiodiversidade $(15 \%)$ ou agropecuárias (16\%) (Figura 1). A novidade, a perspectiva de aceitação no mercado e o aumento da diversidade de alguma variedade resumem os critérios de escolha das variedades que os produtores irão adquirir nas trocas, tendo privilégio aquelas que têm condições de ser cultivadas no espaço disponível, normalmente pequeno. Em geral, relataram que levam uma pequena quantidade de sementes por falta de espaço e também para terem maior controle e observar, primeiramente, como a variedade irá responder. As doações são feitas por vizinhos, amigos, parentes e técnicos representantes de instituições de pesquisa e de assistência técnica, destacando-se as universidades UFRGS e UFPEL, além de Embrapa e CAD/Emater-RS.

Os produtores têm dificuldade com a produção de mudas de certas variedades de hortaliças, o que exige tecnologia e conhecimentos específicos, além da disponibilidade de tempo e mão de obra. $\mathrm{O}$ hábito de comprar mudas de hortaliças é recorrente: quatro produtores entrevistados relatam comprar mudas, três deles quinzenal ou mensalmente, sendo que a produção de um deles é voltada para o autoconsumo, e a compra de mudas é mais esporádica. Foram citadas 24 variedades compradas de mudas (Figura 1), sendo as mais citadas: berinjela, alface e abobrinha. Dentre as mudas, dez são de sementes dos próprios agricultores, que repassam as suas para a empresa que irá produzir as mudas. É uma empresa familiar, que possui uma grande produção de mudas e as fornece para três dos produtores entrevistados e entrega na região metropolitana de Porto Alegre e demais áreas. Um dos produtores, que costuma comprar mudas há mais de dez anos, argumenta que assim obtém uma produção maior do que quando costumava fazer o próprio semeio. A produção de mudas requer conhecimento e tecnologia específicos relacionados à qualidade do substrato, à presença de irrigação e ao local, exigindo qualificação, infraestrutura e disponibilidade de tempo, além do que muitos dos agricultores possuem no momento.

Quanto à compra de sementes, apenas dois agricultores relataram comprar sementes e realizar o seu próprio semeio. Ambos se apropriam das novas variedades, obtendo sucesso em casos como o chingensai ${ }^{4}$, que o produtor reproduz há cinco anos e adquiriu por meio da compra em uma agropecuária, e o quiabo, em que a nova variedade foi incorporada a uma mais antiga que se estava perdendo. Para esses produtores que não costumam comprar mudas, o semeio costuma ser direto, feito em canteiros na roça, ou em uma estrutura com sombrite, que um deles construiu para produzir

4 Variedade de hortaliça folhosa, que se assemelha muito a uma variedade de chicória. 
mudas em canteiros, e também em bandejas de isopor, embora o agricultor seja resistente a produzir em caixas. Esse mesmo produtor desenvolveu um equipamento para semear rúcula em canteiros, que pode ser adaptável a outras variedades. Tanto por meio do plantio direto como no berçário desse produtor, as mudas desenvolvem-se muito próximas e são encontradas em estágios distintos. $\mathrm{O}$ agricultor realiza o manejo do raleio à medida que elas vão desenvolvendo-se e comercializa aquelas com bom tamanho, já que possui uma demanda por folhosas pequenas, vendidas em molho como baby.

Um dos produtores afirmou que diminuiu a diversidade de sua produção, procurando otimizá-la, e optou por variedades mais práticas, como a batata-doce, multiplicável por meio de propágulos vegetativos, e rústica (que exige menos cuidados). No último ano, esse produtor doou para a arca todas as suas sementes de quiabo e fava, que pertenciam à família há gerações, sendo que as sementes de fava foram perdidas. A falta de tempo foi responsabilizada, também, pela perda dos propágulos de morango, que, no entanto, o agricultor recuperou com uma vizinha a quem havia presenteado com a variedade anos atrás. Entretanto, se, por um lado, o produtor teve a diversidade de sua produtividade diminuída, por outro, ele tem mudado suas estratégias e apostado em cultivar arbóreas frutíferas exóticas e nativas da região, que lhe foram doadas por muitas pessoas ao longo de muitos anos, argumentando que está planejando sua aposentadoria, pensando em fortalecer o turismo rural em sua propriedade. Em geral, apenas alguns indivíduos de poucas espécies produzem frutos com capacidade para comercialização, tendo em vista que as propriedades rurais, nessa região da capital, têm pequena área, em torno de 1 ha a 3 ha.

As trocas realizadas durante a Troca Anual de Sementes da Arca de Sementes Berenici Antonini, que ocorre durante a Semana do Alimento Orgânico, são a principal forma de obtenção de novas variedades vegetais pelos integrantes do Opac-Rama. Estes eventualmente participam de outros eventos de troca, como as feiras de troca de sementes crioulas em Ibarama e Novo Hamburgo em 2013. A arca de sementes é mantida pelos sementeiros, que são aqueles produtores que manejam alguma variedade vegetal consigo e abastecem a arca por meio da Troca Anual de Sementes, sendo que a arca existe principalmente devido a esses espaços de troca. $\mathrm{O}$ grupo a considera essencial por promover o resgate e o fortalecimento das variedades.

Segundo um técnico da Emater-RS, a arca possui a ideia central de conservação on farm, feita pelos agricultores a partir de seus próprios métodos e sem a estrutura de um banco de sementes. Um produtor afirmou que um dos principais objetivos da arca é suprir a demanda interna da Rama, além da

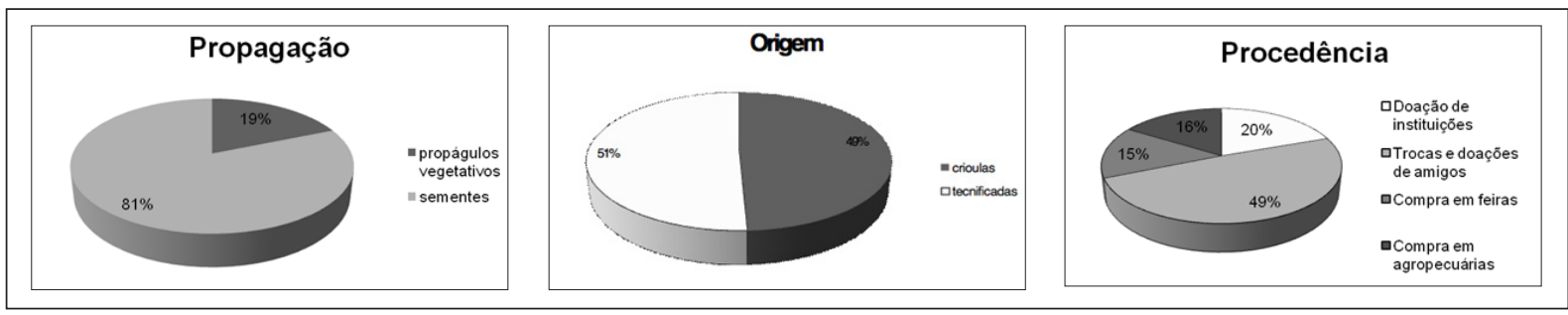

FIGURA 1 - Propagação, origem e procedência das variedades manejadas pelos agricultores do Organismo Participativo de Avaliação da Conformidade da Associação dos Produtores da Rede Agroecológica Metropolitana de Porto Alegre, Rio Grande do Sul. 
necessidade futura de sementes orgânicas para aquisição do selo de certificação. Exemplificou isso por meio de sua iniciativa em cultivar gergelim quando os processadores expuseram que tinham dificuldade em encontrar gergelim orgânico. Praticamente toda a primeira colheita ( $2 \mathrm{~kg}$ de sementes de gergelim) foi distribuída através da arca de sementes.

Os dias da troca são eventos atrativos e objetivam incentivar a permuta de sementes, mudas, propágulos, informações, conhecimentos e estimular mais agricultores a produzirem suas próprias sementes e compartilhá-las. Os entrevistados ressaltaram a importância das trocas para o resgate das variedades, para evitar a erosão genética e para promover a segurança alimentar, além do fato de haver um retorno individual e coletivo, essencial para retroalimentar o grupo. No dia do evento, são registradas as variedades trazidas, quem as doou, qual sua origem e quem as retirou. O retorno da informação de como foi o processo de cultivo da semente é importante para o registro e controle do grupo, assim como para quem for futuramente adquirir a variedade. No encontro de 2015, foram registradas 128 diferentes variedades. Pela primeira vez, por meio de um relato de experiência realizado por uma das representantes do Movimento de $\mathrm{Mu}$ lheres Camponesas de Santa Catarina, convidada a participar e dar seu relato na IV Troca Anual de Sementes, em 2014, houve a iniciativa de misturar as sementes de mesma variedade de diferentes sementeiros com a intenção de evitar a erosão genética, o que foi realizado com as variedades de milho-cunha e com o hibisco. Peroni \& Hanazaki (2002) constataram que agricultores que se baseiam em uma diversidade escassa de cultivares sabem que dependem dos recursos de outros agricultores. Nesses casos, há uma tendência à homogeneização nos cultivos, com aumento da dependência de mercado.
Alguns integrantes consideram que a arca de sementes deveria estar estruturada com o banco de sementes, em que a figura de um guardião seria responsável por guardá-las e armazená-las adequadamente e por controlar os registros. Com relação à demanda por produção de mudas, alguns acham que a solução estaria em alguém especializar-se na produção das mudas orgânicas. No entanto, essa solução é também considerada impraticável, já que um banco de sementes requer mais investimento em infraestrutura. $\mathrm{O}$ produtor considerado o sementeiro-guardião do grupo afirmou que sua preocupação inicial está em suprir sua própria demanda. O grupo concorda que são necessários preocupação e comprometimento de todos, e não apenas do sementeiro-guardião do grupo. De acordo com um técnico da Emater-RS, deve-se iniciar um trabalho para estimular os agricultores a produzir suas próprias mudas. Por outro lado, uma técnica da SDR ressalta que não se deve descuidar da origem da semente.

De acordo com ela, como a Lei dos Orgânicos ainda não restringe o uso de sementes convencionais, os agricultores não estão se preocupando em produzir sua própria semente, e ela acrescenta que, embora seja difícil não recair na lógica de mercado, é preciso falar em produção de sementes para autoconsumo daquelas variedades que forem passíveis de multiplicação. A dependência do mercado para a aquisição de sementes foi um dos temas de preocupação dos produtores e também amplamente debatido no curso de produção agroecológica de sementes de hortaliças. Contraditoriamente, a proposta aparece para estimular os produtores a continuar fornecendo sementes para outros do grupo. No entanto, a comercialização impõe um maior controle de qualidade sobre as sementes, o que afugenta os sementeiros. A Lei de Sementes brasileira, no entanto, não estabelece nenhuma res- 
trição à venda de sementes, desde que seja realizada entre agricultores familiares, assentados da reforma agrária e indígenas (Santilli, 2009).

As discordâncias que surgem no grupo em relação às perspectivas quanto à arca de sementes, que alguns idealizam por meio da figura de um guardião de sementes, e outros, de diversos sementeiros, são facilmente relacionáveis ao perfil diversificado do grupo, formado por pessoas com percursos de vida distintos. No entanto, esperar que a questão logística da produção de mudas ou a disponibilidade de sementes orgânicas sejam resolvidas a partir da figura de um agricultor é inviável a princípio e parece estar em conflito com a proposta de construção participativa do grupo. Há relatos desejando uma mudança interna de comportamento dos integrantes do grupo, referindo-se à falta de coesão e de coletividade, além de considerar que ele precisa se qualificar com relação à produção e à troca de sementes. A forma como os integrantes se relacionam e priorizam a questão é diversa também: enquanto um produtor entrevistado afirmou não ter tempo para guardar e cuidar de suas sementes, outro produtor demonstrou mais facilidade em ter sua própria produção, argumentando não depender do mercado de sementes e alertando que o grupo não está consciente e continua optando pela praticidade em comprar mudas.

O representante do Mapa presente em uma das plenárias explicou que o Opac enquanto processo participativo, não faz apenas parte de um sistema de certificação. Ele é também considerado um mecanismo propulsor da agroecologia no país e, portanto, é preciso contribuir para esse processo de transição dos indivíduos e do grupo, em vez de ter uma atitude individualista e fiscalizadora dos outros. Ploeg (2008) afirma que a ideia da reciprocidade se mostra mais vantajosa, especialmente quando se transforma em um mecanismo para manter a qualidade. Quando não há rupturas nas trocas mútuas, a reciprocidade impede o oportunismo que é intrínseco ao funcionamento do mercado. A agroecologia contém um entendimento dos níveis ecológicos e sociais de coevolução, estrutura e funcionamento que busca promover a diversificação inter e intraespecífica no agroecossistema por meio de metodologias que valorizem a participação dos agricultores, o conhecimento tradicional e a adaptação da atividade agrícola às necessidades locais e às condições socioeconômicas e biofísicas (Altieri, 2012).

Para o Opac-Rama, a arca de sementes e os eventos de troca estimulam a conscientização sobre a origem das sementes e contribuem para a união e a solidariedade entre o grupo pela consagração pessoal e da simbologia contida na troca de sementes. Nesses momentos, os agricultores têm a possibilidade de entrar em contato com uma maior diversidade biológica, incluindo muitas variedades que não estão presentes no mercado convencional.

\section{Considerações finais: a vulnerabilidade dos sistemas tradicionais de manejo de sementes crioulas - o caso do Opac-Rama}

As sementes crioulas pertencem aos agricultores, sendo cultivadas e selecionadas ao longo de gerações, o que as torna adaptadas às condições e aos sistemas de produção locais, e atendem às necessidades de seus manejadores. Ter sua semente própria e de qualidade é uma das etapas mais importantes no processo de transição agroecológica, a qual consolida a autonomia do agricultor. Em contraposição, as sementes tecnificadas são produzidas pelas empresas para responder a uma agricultura baseada em insumos químicos e reduzir o agricultor a mais uma das etapas da produção 
de cadeias produtivas pautadas por uma matriz energética dependente de petróleo.

A iminência da obrigatoriedade do uso de sementes provenientes de sistemas orgânicos para obter a certificação orgânica pôs em evidência a ineficiência do sistema formal de sementes - o qual é legitimado por meio das leis de proteção de cultivares e de sementes - em suprir a demanda de sementes dos sistemas locais por parte dos agricultores orgânicos, que ainda possuem um mercado de sementes orgânicas muito restrito. Shiva (2003) destaca que, sob a perspectiva hegemônica de maximização em nível local, parte essencial da agrobiodiversidade é considerada dispensável, excluindo as espécies que não são úteis do ponto de vista mercadológico da produção, o que significa perda de agrobiodiversidade, de conhecimentos tradicionais e de fontes nutritivas para comunidades locais, sendo um exemplo as Pancs.

A partir desta pesquisa, evidenciaram-se algumas dificuldades que o grupo enfrenta para obter autonomia em relação às sementes e mudas orgânicas, destacando-se aquelas variedades produzidas em maior escala, muitas híbridas, de consumo amplamente difundido, que tornam os agricultores dependentes dessa relação com o mercado convencional de sementes. A produção de hortaliças, em geral, é feita por intermédio do transplante de mudas, sendo a compra delas a alternativa mais prática, o que torna os produtores dependentes da compra de sementes e mudas a cada nova safra. Mesmo sendo dependentes do mercado para as hortaliças, os agricultores entrevistados manejam 49,3\% de suas variedades (Figura 1), consideradas crioulas (Tabela 1), as quais estão sendo conduzidas em seus processos de domesticação.
Altieri (2012) e Santilli (2009) destacam que as ações dos agricultores em direção à autonomia também ocorrem à medida que eles se apropriam do processo de manejo das espécies tecnificadas. Trata-se de um processo de reapropriação dos ciclos reprodutivos completos de suas variedades. No caso do Opac-Rama, esse processo ocorreu com a variedade chingensai, e os agricultores passaram a conduzir o ciclo completo da espécie e a produzir sua própria semente.

A disponibilidade e o acesso a sementes orgânicas e crioulas no mercado formal são limitados, sendo que, em se tratando de sementes orgânicas de hortaliças, as possibilidades se restringem, basicamente, ao fornecimento pela empresa Bionatur ${ }^{5}$, que também encontra obstáculos para se manter. As limitações impostas pela Lei de Sementes brasileira, formulada com o objetivo de fortalecer a atuação dos atores hegemônicos no mercado de sementes, geram diversos obstáculos para a diversificação das variedades fornecidas pela empresa, pela dificuldade de acesso a sementes básicas e a sementes sem mantenedores, que restringem a disponibilidade àquelas convencionais, e as exigências são estabelecidas pelo sistema de produção formal de sementes, quanto ao controle da produção extremamente onerosa para as pequenas empresas de sementes (Reis, 2012).

A compra de sementes da empresa ISLA (da linha sem defensivos), somada ao estímulo pela produção própria de mudas, foi apontada como uma das soluções para aquelas variedades em que a demanda não é atendida pela falta de disponibilidade de sementes orgânicas. A IN n 46 (MAPA, 2011) prevê que, quando não houver disponibilidade de sementes provenientes do sistema orgânico, os

\footnotetext{
5 A Bionatur é uma empresa social do Movimento dos Trabalhadores Rurais Sem Terra, especializada na produção de sementes agroecológicas de hortaliças.
} 
produtores poderão utilizar variedades do sistema convencional, dando preferência àquelas sem agrotóxicos, quando autorizados pela OAC ou OCS de que fazem parte. A legislação dos orgânicos, tendo por objetivo fortalecer a agroecologia, deve facilitar a transição agroecológica, não impondo inúmeras restrições ao mercado dos orgânicos a ponto de desestimular os produtores (MAPA, 2013). A fiscalização deve atuar também de forma propositiva, a fim de estimular e promover a agroecologia. $\mathrm{O}$ Plano Nacional de Agroecologia e Produção Orgânica (Planapo), instrumento de execução da Política Nacional de Agroecologia e Produção Orgânica (Pnapo), estabelece como uma de suas diretrizes promover a valorização da agrobiodiversidade e dos produtos da sociobiodiversidade e estimular as experiências locais de uso, conservação e manejo dos recursos genéticos vegetais e animais. Prevê, ainda, a aquisição e distribuição de recursos genéticos - entre eles, sementes crioulas, varietais, orgânicas e agroecológicas (CIAPO, 2013).

Ao longo da pesquisa, observou-se que os agricultores optam por estratégias de produção distintas, e pode-se constatar que desconsideram outros aspectos importantes para a consolidação do processo de transição agroecológica, como a questão do manejo das sementes. Essa situação decorre do fato de que esses produtores estão pressionados pelas atividades rotineiras estabelecidas ao longo da semana, com o foco na comercialização nas feiras ecológicas semanais, e limitados pelo longo tempo exigido para o trabalho na roça, já que a mão de obra é bastante escassa. Nesse contexto, os agricultores optam por diferentes estratégias. Em busca de uma produção mais agroecológica, ainda que muito dependentes de insumos externos e das relações de mercado, eles diversificam sua produção com variedades com as quais têm mais afinidade. As estratégias para o agricultor que procura obter autonomia em colher suas próprias sementes e produzir suas mudas variam entre conversão de canteiros de hortaliças e canteiros agroflorestais com plantio de frutíferas nativas e exóticas e promoção de Pancs utilizadas principalmente para o autoconsumo, eventualmente também processadas e comercializadas.

De uma maneira geral, o grupo está despertando para a questão da conservação das sementes e primando pelo controle e registro da origem delas, a partir da iminente imposição do uso de sementes orgânicas. Ao mesmo tempo, parte do grupo ainda espera que a demanda por mudas e sementes seja resolvida internamente, a partir de alguém que se especialize nessa produção. Entretanto, ninguém manifestou esse interesse. Um dos produtores, com potencial para se destacar como sementeiro do grupo, declarou que está, primeiramente, em busca de sua própria autonomia. Embora destine parte de sua produção às trocas, considera que suprir a demanda do grupo é uma grande responsabilidade, à qual não se habilita neste momento. Ademais, esse mesmo agricultor manifesta não compactuar com a comercialização de sementes dentro do grupo, sendo essa uma das soluções apontadas para valorizar a dedicação a esse trabalho de conservação e multiplicação - experiência também relatada por Reis (2012). Dessa forma, o acesso dos agricultores a variedades não tecnificadas está condicionado ao sistema de sementes locais, sendo que essas variedades são mantidas há mais tempo pelos agricultores, adquiridas mediante trocas e como presente de vizinhos e parentes.

O grupo está fortalecendo o processo de transição agroecológica e busca por autonomia. Apesar de ainda serem restritas a um dia no ano, as práticas de troca de sementes e de informação estão sendo estimuladas por meio da Troca Anual de Sementes, processo que tem apresentado conti- 
nuidade. Portanto, se, por um lado, os agricultores têm dificuldade em se sustentar com uma produção diversa em produtos da agrobiodiversidade e apostam na produção, em maior escala, de algumas poucas variedades, submetendo-se ao mercado de sementes e mudas convencionais, por outro, esses mesmos agricultores mantêm uma diversidade considerável de variedades crioulas, selecionadas ao longo de anos, em pequena escala.

No momento atual, o sucesso na autonomia da produção de suas sementes é o processo fundamental a ser implementado para a obtenção da produção agroecológica do grupo. Essa condição impõe o desafio de buscar alternativas que tensionam as lógicas mercadológica e de reciprocidade, bem como $\mathrm{o}$ individualismo e a coletividade. $\mathrm{O}$ caso estudado evidencia que políticas de fortalecimento dos processos de troca de sementes entre grupos de agricultores se configuram como a ação de maior potência para o fortalecimento da produção agroecológica, tanto pelas trocas de sementes, propriamente ditas, quanto por propiciarem a interação entre grupos de agricultores. Esses processos fortalecem as redes agroecológicas e incentivam a criação, entre os grupos, de mecanismos de compensação aos agricultores que sejam suficientemente atrativos e que, por vezes, se encontrem fora da lógica de mercado

\section{Referências}

Albuquerque, U. P. de; Lucena, R. F. P. (Orgs.). Métodos e técnicas de pesquisa etnobotânica. 1. ed. Recife: LivroRápido/NUPEEA, 2004.

Altieri, M. Agroecologia: bases científicas para uma agricultura sustentável. São Paulo, Rio de Janeiro: Expressão Popular, AS-PTA, 2012. para aqueles que estejam dispostos a assumir o papel de guardiões de sementes.

A partir do caso do Opac-Rama, percebe-se que, apesar da forte pressão que a legislação de proteção de cultivares exerce sobre seus processos de autonomia, buscando mantê-los como elos das cadeias produtivas agrícolas, a atual legislação de orgânicos está incentivando a retomada do manejo de sementes crioulas por grupos de agricultores organizados. Portanto, mesmo em um cenário brasileiro em que os cultivares melhorados e homogêneos são largamente incentivados, os direitos dos agricultores aos seus conhecimentos e práticas de manejo de suas sementes crioulas estão resistindo e buscando se viabilizar, fortalecendo assim os processos agroecológicos.

\section{Agradecimentos}

Somos gratas à Associação dos Produtores da Rede Agroecológica Metropolitana de Porto Alegre, assim como a seus integrantes, pela participação e disponibilidade para o desenvolvimento desta pesquisa, e aos técnicos da Emater-RS e SDR-RS que participaram das entrevistas, em especial a Agda Regina Yatsuda Ikuta e ao professor Paulo Brack, que deram suas contribuições a este trabalho.

Amorozo, M. C. de M. Sistemas agrícolas de pequena escala e a manutenção da agrobiodiversidade: uma revisão e contribuições. 1. ed. Rio Claro: FCA - UNESP, 2013.

Bardin, L. Análise de conteúdo. Lisboa: Persona, 1977. Disponível em: <pt.slideshare.net/RonanTocafundo/ bardin-laurence-anlise-de-contedo? related $=1>$. Acesso em: jan. 2015. 
Brasil. Lei $n^{\circ}$ 9.456, de 25 de abril de 1997. Institui a Lei de Proteção de Cultivares e dá outras providências. Brasília, DF, 1997. DOU 28/4/1997.

Brasil. Lei ${ }^{\circ} 10.711$, de 5 de agosto de 2003. Dispõe sobre o Sistema Nacional de Sementes e Mudas e dá outras providências. Brasília, DF, 2003a. DOU 6/8/2003.

Brasil. Lei $n^{\circ} 10.831$, de 23 de dezembro de 2003. Dispõe sobre a agricultura orgânica e dá outras providências. Brasília, DF, 2003b. DOU 24/12/2003.

Brasil. Decreto $n^{\circ}$ 6.323, de 27 de dezembro de 2007. Regulamenta a Lei $\mathrm{n}^{\circ} 10.831$, de 23 de dezembro de 2003, que dispõe sobre a agricultura orgânica, e dá outras providências. Brasília, DF, 2007a. DOU 28/12/2007.

Brush, S. B. Genes in the field: on-farm conservation of crop diversity. Ottawa, Canada: International Development Research Centre, 2000.

Clement, C. R. 1492 and the loss of Amazonian crop genetic resources. I The relation between domestication and human population decline. Economic Botany, 53(2), 188-202, 1999.

Stuart Coupe, S.; Lewins, R. Negotiating the seed treaty. Bourton on Dunsmore, UK: Practical Action Publishing, 2007.

Ciapo - Câmara Interministerial de Agroecologia e Produção Orgânica. Plano Nacional de Agroecologia e Produção Orgânica - PLANAPO. Brasília, DF: MDS; CIAPO, 2013. Disponível em: <www.mda.gov.br/sitemda/sites/ sitemda/files/user_img_19/BrasilAgroecologico_Baixar. pdf $>$. Acesso em: fev. 2015.

Cunha, M. C. da. Cultura com aspas e outros ensaios. São Paulo: Cosac Naify, 2009.

Declaração de Roma Sobre a Segurança Alimentar Mundial e Plano de Acção da Cimeira Mundial da Alimentação. World Food Summit, 1996. Disponível em: <www.fao. org/docrep/003/W3613P/W3613P00.htm>. Acesso em: nov. 2016

Fonseca, M. F. de A. C. Agricultura orgânica: regulamentos técnicos para acesso aos mercados dos produtos orgânicos no Brasil. Niterói: Pesagro-Rio, 2009.

Goodman, D.; Sorj, B.; Wilkinson, J. Da lavoura às biotecnologias: agricultura e indústria no sistema internacional. Rio de Janeiro: Campus, 1990.
Harlan, J. K. Crops and Man. Madison: American Society of Agronomy, 1992.

Kinupp, F. V. Plantas alimentícias não-convencionais da Região Metropolitana de Porto Alegre. Porto Alegre, Tese (Doutorado em Fitotecnia) - UFRGS, 2008.

Machado, A. T.; Santilli, J.; Magalhães, R. A agrobiodiversidade com enfoque agroecológico: implicaç,ões conceituais e jurídicas. Brasília, DF: Embrapa Informação Tecnológica, 2008.

MAPA - Ministério da Agricultura, Abastecimento e Pecuária. Instrução Normativa $n^{\circ} 64$, de 18 de dezembro de 2008. DOU 19/12/2008.

MAPA - Ministério da Agricultura, Abastecimento e Pecuária. Instrução Normativa $n^{\circ} 46$, de 6 de outubro de 2011, regulada pela Instrução Normativa nº 17, de 2014. DOU 7/10/2011.

MAPA - Ministério da Agricultura, Abastecimento e Pecuária. Instrução Normativa no ${ }^{\circ}$, de 18 de junho de 2014. DOU 20/06/2014.

MAPA - Ministério da Agricultura, Abastecimento e Pecuária. Adiada a obrigatoriedade do uso de sementes orgânicas. Notícia publicada em 2013. Disponível em: $<$ www.agricultura.gov.br/vegetal/noticias/2013/12/adiada-a-obrigatoriedade-do-uso-de-sementes-organicas $>$. Acesso em: jan. 2015.

Mazoyer, M., Roudart, L. História das agriculturas no mundo: do neolítico à crise contemporânea. São Paulo: Editora UNESP; Brasília, DF: NEAD, 2010.

Medeiros, M. F. T.; Albuquerque, U. P. de. (Org.). Dicionário Brasileiro de Etnobiologia e Etnoecologia. 1. ed. Recife: NUPEEA, 2012.

Peroni, N.; Hanazaki, N. Current and lost diversity of cultivated varieties, especially cassava, under swidden cultivation systems in the Brazilian Atlantic Forest. Agriculture, Ecosystems and Environment, 92, 171-183, 2002. doi: 10.1016/S0167-8809(01)00298-5

Ploeg, J. Camponeses e impérios alimentares: lutas por autonomia e sustentabilidade na era da globalização. Porto Alegre: Ed. UFRGS, 2008.

RAMA. OPAC RAMA. Panfleto de divulgação, 2012?. 
Reis, M. R. Tecnologia social de produção de sementes e agrobiodiversidade. Brasília, Dissertação (Mestrado em Desenvolvimento Sustentável) - UnB, 2012.

Santilli, J. Agrobiodiversidade e direitos dos agricultores. São Paulo: Peirópolis, 2009.
Shiva, V. Monoculturas da mente: perspectivas da biodiversidade e da biotecnologia. São Paulo: Gaia, 2003.

Uriartt, A. H. et al. Formação da Organização de Controle Social - OCS - Porto Alegre/Viamão-RS: construindo novas relações de produção e consumo. Agroecologia e Desenvolvimento Rural Sustentável, 4(1), 9-14, 2011. 